\title{
Bcl10 crucially nucleates the pro-apoptotic complexes comprising PDK1, PKC $\zeta$ and caspase-3 at the nuclear envelope of etoposide-treated human cervical carcinoma $\mathrm{C} 4$-I cells
}

\author{
ANNA CHIARINI $^{1}$, DAISONG LIU ${ }^{2}$, UBALDO ARMATO ${ }^{1}$ and ILARIA DAL PRÀ ${ }^{1}$ \\ ${ }^{1}$ Histology and Embryology Section, Department of Life and Reproduction Sciences, University of Verona Medical School, \\ I-37134 Verona, Venetia, Italy; ${ }^{2}$ Chongqing Key Laboratory for Disease Proteomics, Institute of Burn Research, \\ Southwest Hospital, Third Military Medical University, Chongqing 400038, P.R. China
}

Received April 7, 2015; Accepted July 2, 2015

DOI: $10.3892 / \mathrm{ijmm} .2015 .2290$

\begin{abstract}
Protein kinase (PK)C $\zeta$ signaling at various subcellular levels affects cell survival, differentiation, growth and/or apoptosis. However, the mechanisms modulating $\mathrm{PKC} \zeta$ activity at the nuclear membrane (NM) are not yet fully understood. Previously, we demonstrated that $\mathrm{PKC} \zeta$ interacts with the B-cell lymphoma 10 (Bcl10) protein at the NM of human cervical carcinoma (HCC) C4-I cells. In the present study, we aimed to further clarify the interactions between $\mathrm{PKC} \zeta, \mathrm{Bcl} 10$ and other proteins co-immunoprecipitated from NMs isolated from untreated and etoposide (also known as VP-16;2.0 $\mu \mathrm{g} / \mathrm{ml}$ )-treated C4-I cells using biochemical and proteomics analyses. Aside from the Bcl10 protein, 3-phosphoinositide-dependent protein kinase-1 (PDK1) also co-immunoprecipitated with $\mathrm{PKC} \zeta$ from NMs of C4-I cells, indicating the assembly of a heterotrimeric complex, which increased with time in VP-16-exposed cells, as did the activity of PDK1-phosphorylated-PKC $\zeta$. In turn, PKC $\zeta$-phosphorylated-Bcl10 straddled an enlarged complex which comprised caspase-3. Subsequently, activity-enhanced caspase- 3 cleaved and inactivated PKC $\zeta$. Finally, the suppression of Bcl10 using specific siRNA or lentiviral transduction prevented the increase in the PDK $1 \bullet \mathrm{PKC} \zeta$ association, the increase in the activity of $\mathrm{PKC} \zeta$ and caspase-3, as well as the caspase-3-mediated $\mathrm{PKC} \zeta$ proteolysis and inactivation from
\end{abstract}

Correspondence to: Dr Anna Chiarini, Histology and Embryology Section, Department of Life and Reproduction Sciences, University of Verona Medical School, 8 Strada Le Grazie, I-37134 Verona, Veneto, Italy

E-mail: anchiari@gmail.com

Abbreviations: inv, non-target vector; HCC, human cervical carcinoma; $i B c l 10$, short hairpin Bcl10 mRNA-suppressing lentiviral vector; NE, nuclear envelope; NM, nuclear membrane; PDK1, 3-phosphoinositide-dependent protein kinase-1; PK, protein kinase; siBcl10, small interfering RNA mediating Bcl10 suppression; TCL, total cell lysate; wt, wild-type

Key words: Bcl10, protein kinase $\mathrm{C} \xi$, 3-phosphoinositide-dependent protein kinase-1, caspase-3, C4-I cells, apoptosis, nuclear envelope occurring at the NMs of the VP-16-exposed C4-I cells. Our observations provide evidence that $\mathrm{Bcl10}$ acts as a pivotal pro-apoptotic protein which crucially nucleates complexes comprising PDK1, PKC $\zeta$ and active caspase-3 at the NMs of VP-16-exposed C4-I cells. Hence, our data suggest that Bcl10 and $\mathrm{PKC} \zeta$ are potential therapeutic targets in the treatment of HCC.

\section{Introduction}

The disease with the second highest rate of mortality, for women, is human cervical carcinoma (HCC), which is prevalent in developing countries $(1,2)$. The majority of HCCs derive from epithelial cells that have been persistently infected with high-risk oncogenic human papillomaviruses (HPVs), which express the E6 and E7 mRNAs, and proteins binding/neutralizing anti-oncogenic p53 and pRb. Furthermore, other co-factors, which have been less thoroughly studied, also promote HCC development $(3,4)$. Notably, a small percentage $(10 \%)$ of HCCs develops independently of a persistent high-risk oncogenic HPV infection (5). The complex molecular mechanisms responsible for the development of HCCs thus remain partially unclear, and this hinders the identification of predictive markers for the early detection of malignancy development and the discovery of novel, effective therapies.

Proteomics and bioinformatics analysis have allowed researchers to identify differential protein expression patterns and the molecular mechanisms responsible for the development of HCC (6). A previous study identified a consensus of 66 proteins termed the 'central core of HCC protein expression' which was deduced from the proteomes of 6 HCC cell lines (not comprising the $\mathrm{C} 4$-I cell line); this differed from the proteomic profile corresponding to the non-tumorigenic cell line, $\mathrm{HaCaT}$ keratinocytes (7). Conversely, a comparative transcriptomics study carried out on 9 HCC cell lines singled out C4-I cells as those which mimicked most closely late-stage invasive in vivo HCCs (8). This prompted us to select the C4-I cells as our experimental model in order to study the signaling of protein kinase $\mathrm{C}(\mathrm{PK}) \mathrm{C}$ isoforms at the nuclear envelope (NE) under conditions of spontaneous growth or apoptosis. 
PKCs include 12 gene-related serine/threonine PK isoforms, which play crucial roles in cell survival, differentiation, polarity regulation, gene transcription, mitotic cycle control, malignant initiation and promotion, and drug- or irradiation-elicited apoptosis (1,9-13). On the basis of their activation requirements, the PKC isoforms are divided as follows: i) classical PKCs [cPKCs, i.e., $\alpha, \beta \mathrm{I}, \beta \mathrm{II}$ and $\gamma$, the activation of which requires calcium, diacylglycerol (DAG) and phosphatidylserine (PS)]; ii) novel PKCs (nPKCs, i.e., $\delta, \varepsilon, \eta$ and $\theta$, the activation of which requires DAG and PS, but not calcium); and iii) atypical PKCs (aPKCs, i.e., $\zeta$ and $\mathrm{s} / \lambda$, the activation of which requires only PS). Each $\mathrm{PKC}$ isoform has unique structural properties and different subcellular locations, and each has a different signaling role according to cell type and subcellular compartment, e.g., the endoplasmic reticulum (ER), mitochondria and NE (9-13).

The many functions of the NE are of great pathophysiological importance: it has been shown to play important roles in the upkeep of the nuclear integrity, in chromatin organization control and maintenance, the sequestration of transcription factors, gene transcription, DNA replication, cell development, cell differentiation, signaling molecule production and activity, and it is also involved in protecting cells against stress (14). However, the roles of PKC isoform(s) signaling at the NE, particularly in apoptotic cells, are not yet fully understood. Previously, using pyF111 cells, i.e., polyomavirus (the rodent HPV counterpart)-infected rat embryo fibroblasts, we demonstrated that various PKC isoforms (e.g., $\beta \mathrm{I}, \beta \mathrm{II}$ and $\delta$ ) translocated to the NE and there exhibit an increase or decrease in activity during apoptosis induced by etoposide (also known as VP-16, a topoisomerase-II inhibitor) or photoexcited calphostin-C (15-18). Etoposide is a drug that is used to treat several types of cancer, including cervical carcinoma; several clinical studies have suggested that the combination of etoposide with cisplatin is effective for treating advanced or recurrent cervical cancers (19).

Therefore, in a recent study of ours (20), we aimed to elucidate, by means of proteomic and biochemical methods, the interactions of PKC $\zeta$ isoforms with protein partners at the nuclear membranes (NMs) of both spontaneously proliferating (i.e., untreated) and apoptotic (i.e., VP-16-exposed) HCC C4-I cells. Through the combined use of two-dimensional electrophoresis (2-DE), matrix-assisted laser desorption ionization (MALDI) time-of-flight (TOF) mass spectrometry (MS), peptide mass fingerprinting (PMF), and bioinformatics analysis, we selected 31 and 33 proteins which co-immunoprecipitated with PKC $\zeta$ from the NMs of untreated or VP-16-exposed C4-I cells, respectively. These proteins pertained to 8 functional groups, the members and relative sizes of which differed. Of the proteins detected, only 8 proteins, including B-cell lymphoma 10 (Bcl10) were belonged to both subproteomes. Therefore, given the highly dynamic complexity of the NM-linked interactors/substrates, the molecular interactions and functional roles of PKC $\zeta$ changed remarkably, in keeping with the untreated or apoptogen-treated cellular contexts (20). Moreover, we unexpectedly found that at the NMs of VP-16-treated C4-I cells, PKC $\zeta$ formed complexes with and phosphorylated the Bcl10 protein, which prompted the caspase-3-mediated pro-apoptotic inactivation of PKC $\zeta$ (20).

The $B c l 10$ gene was identified from the $(1 ; 14)(\mathrm{p} 22 ; \mathrm{q} 32)$ breakpoint in mucosa-associated lymphoid tissue (MALT) lymphomas and is ubiquitously expressed in normal tissues (21).
It encodes a 233 amino acid protein that has an $\mathrm{N}$-terminal domain (amino acids 1-13) necessary for transcriptional activation $(22,23)$, a caspase recruitment domain (CARD; amino acids 14-90) to which CARD motif-endowed proteins [e.g., CARD-containing MAGUK protein 1 (CARMA1)] bind (21), and a C-terminal region (amino acids 91-233) rich in serines and threonines that undergoes multiple phosphorylations (24). The Bcl10 protein functions are manifold. Previous gene-knockout research has identified $\mathrm{BcllO}$ as a positive regulator of neural tube closure and of the antigen receptor-induced activation of nuclear factor- $\kappa \mathrm{B}(\mathrm{NF}-\kappa \mathrm{B})$, a transcription factor involved in cell survival, lymphocyte proliferation and normal immune responses (25). Wild-type (wt) $\mathrm{BcllO}$ operates as a tumor suppressor, whereas mutated $B c l 10$ acquires oncogenic properties that act to promote various lymphomas and mesotheliomas $(21,26)$. However, no $\mathrm{BcllO}$ mutations have been detected in many other types of human solid tumors, including HCCs $(21,27)$. Conversely, the pathophysiological mechanism(s) mediated by the Bcl10 protein during apoptosis has(ve) not, as yet, been fully elucidated. It has been reported that the enforced overexpression of wt Bcl10 protein weakly induces apoptosis and activates NF- $\mathrm{BB}$ in cells; yet, the expression of a Bcl10 mutant protein, in which the CARD domain is truncated, does not trigger apoptosis but activates NF- $\mathrm{B}(26,28,29)$. Evidence to date suggests that the Bcl10 protein is involved in the autoproteolytic activation of pro-caspase-9 (28), in dissociating caspases from their inhibitors, cellular inhibitor of apoptosis proteins (cIAPs) (30), and in the formation of pro-apoptotic complexes with PKC $\zeta$ at the NMs of HCC C4-I cells $(20,31)$.

In our previous study, of the proteins that co-immunoprecipitated with $\mathrm{PKC} \zeta$ from the NMs, we identified the 3-phosphoinositide-dependent protein kinase-1 (PDK1) (20), a master regulator of the AGC family of PKs. PDK1 mediates various important cellular functions, and it phosphorylates and activates several AGC-family members involved in the modulation of cell growth, proliferation, survival and metabolism (32). PDK1 is a constitutively active kinase that phosphorylates other members of the same family, i.e., PKCs, S6K, SGKs, p90 ibosomal protein S6 kinases (RSKs) and AKT at their activation loop (residue $\mathrm{Thr}^{308}$ or equivalent). Therefore, the specificity of the functions of PDK1 is ensured by its location near its downstream targets and by protein-protein interactions (33-35). Previously, PDK1 has been shown to play a crucial nucleating role in $\mathrm{T}$ cells by connecting the $\mathrm{T}$ cell receptor (TCR) to two signaling complexes, $\mathrm{PKC} \theta / \mathrm{IKK}$ and CARMA1/Bcl10/MALT1 (or CBM signalosome), triggering $\mathrm{NF}-\kappa \mathrm{B}$ activation in response to TCR signaling (36).

The present study aimed to further define the interactive roles Bcl10 plays not only with $\mathrm{PKC} \zeta$, but also with PDK1 and caspase-3 at the NMs of apoptotic C4-I cells. Our results support the hypothesis that Bcl10 protein functions as an essential 'linchpin' which nucleates pro-apoptotic complexes comprising PDK1, PKC $\zeta$ and caspase-3 at the NMs of VP-16-treated C4-I cells.

\section{Materials and methods}

Cell culture. The HCC C4-I cells were a gift from Professor Nelly Auersperg (University of British Columbia, Vancouver, $\mathrm{BC}$, Canada). The cells were plated in $175-\mathrm{cm}^{2}$ plastic 
flasks (Sarstedt, Verona, Italy) and incubated at $37^{\circ} \mathrm{C}$ in $95 \%$ air $/ 5 \% \mathrm{CO}_{2}$ in complete medium consisting of $95 \%(\mathrm{v} / \mathrm{v})$ Dulbecco's modified Eagle's Minimum Essential Medium (MEM; Sigma-Aldrich, Milan, Italy) and 5\% (v/v) heat-inactivated $\left(56^{\circ} \mathrm{C}\right.$ for $30 \mathrm{~min}$ ) fetal bovine serum (Lonza Group, Ltd., Basel, Switzerland) containing gentamycin $(0.1 \mathrm{mg} / \mathrm{ml}$; Lonza Group, Ltd.). Prior to reaching confluence, the cell cultures were split at a ratio of $1: 6$ by incubating them at $18 \pm 2{ }^{\circ} \mathrm{C}$ with $0.025 \%(\mathrm{w} / \mathrm{v})$ trypsin (Sigma-Aldrich).

Cell apoptosis. The cells were seeded $\left(0.8 \times 10^{6}\right.$ cells $)$ in each of several $175-\mathrm{cm}^{2}$ flasks. At the $0 \mathrm{~h}$ of the experiment (i.e., $24 \mathrm{~h}$ later), the cells in some flasks were sampled (untreated controls), while the topoisomerase-II inhibitor, VP-16 (etoposide or 4-demethyl-epipodophyllotoxin-9-[4,6- $O$-ethylidene- $\beta$-Dglucopyranoside); $2.0 \mu \mathrm{g} / \mathrm{ml}$; Sigma-Aldrich) was added to the remaining flasks. The medium was not changed during the observation period ( 48 or $72 \mathrm{~h}$ ). In order to assess cell damage by epifluorescence microscopy, the cells were stained with acridine orange (AO) and ethidium bromide (EB), which simultaneously revealed viable, apoptotic and necrotic cells.

Isolation of nuclei and NMfractions. The cells were harvested by scraping them into cold $\left(4^{\circ} \mathrm{C}\right)$ phosphate-buffered saline (PBS) and centrifuging the suspension at $200 \mathrm{x}$ g for $10 \mathrm{~min}$. To isolate the nuclei and NEs, cell fractionations were carried out as previously described (20). The integrity of the nuclei was judged by phase contrast microscopy, and the purity of the NMs was assessed by western blot analysis with an anti-lamin B1 (C-20) goat antibody (sc-6216; Santa Cruz Biotechnology, Inc., Heidelberg, Germany). The nuclei were suspended in an excess volume of hypotonic buffer [10 mM Tris ( $\mathrm{pH} 7.4), 10 \mathrm{mM}$ $\mathrm{Na}_{2} \mathrm{HPO}_{4}, 5 \mathrm{mM}$ sodium fluoride, $20 \mu \mathrm{M}$ sodium orthovanadate and complete EDTA-free protease inhibitor mixture (Roche Diagnostics $\mathrm{GmbH}$, Milan, Italy)] containing DNAse I and heparin $(0.2$ and $5.0 \mathrm{mg} / \mathrm{mg}$ of nuclear protein, respectively). This suspension was incubated at $4^{\circ} \mathrm{C}$ for $45 \mathrm{~min}$ and then centrifuged at $9,500 \mathrm{x}$ g for $15 \mathrm{~min}$. The resulting pellet was the NE-enriched NM fraction, while the supernatant was the nucleoplasmic (NP) fraction. In this study, we focused on NMs, but also probed total cell lysates (TCLs) as required.

Immunoprecipitation of NM-bound proteins. Equal amounts of protein $(150 \mu \mathrm{g})$ from the NMs were used in the immunoprecipitation experiments, which were performed with Dynabeads Protein G (Life Technologies Italia, Monza, Italy) and antibodies against PKC' (sc-216), PDK1 (sc-17766) or Bcl10 (sc-5273 mouse monoclonal or sc-5611 rabbit polyclonal; Santa Cruz Biotechnology, Inc.) according to the manufacturer's instructions. The immunocomplex-bearing beads were washed 5 times with Tris-buffered saline [20 mM Tris (pH 7.4), $200 \mathrm{mM} \mathrm{NaCl}$ ], $5 \mathrm{mM}$ sodium fluoride, $20 \mu \mathrm{M}$ sodium orthovanadate, and complete EDTA-free protease inhibitor mixture (Roche Diagnostics $\mathrm{GmbH})$. After a final wash, the immunocomplex-bearing beads were resuspended in tris-buffered saline to measure PKC $\zeta$ native activity or in sample buffer for western blot analysis.

Western blotanalysis. Equal amounts (10-20 $\mu \mathrm{g})$ of protein from each subcellular fraction were determined by means of Bio-rad Protein Assay (Bio-rad Laboratories, Milan,Italy) and processed for western blot analysis as previously described $(15-18,20)$. Different antibodies (final concentration, $1.0 \mu \mathrm{g} / \mathrm{ml}$ ) were used to for antigen detection: anti-PKC $\zeta$ (C-20; sc-216), anti-[pho sphorylated (p)-Thr ${ }^{410}$ ]-PKC $\zeta$ (sc-101778), anti-Bcl10 (331.3 sc-5273 mouse monoclonal or $\mathrm{H}-197 \mathrm{sc}-5611$ rabbit polyclonal), anti-PDK1 (A-10; sc-17766) and anti-Lamin B1 (C-20; sc-6216; this antibody was used to reveal equal loading of proteins) (all from Santa Cruz Biotechnology, Inc.). The blots were then incubated with alkaline phosphatase-conjugated anti-mouse, anti-rabbit or anti-goat IgGs (Santa Cruz Biotechnology, Inc.) and stained with BCIP/NBT liquid substrate reagent or CDP-Star (both from Sigma-Aldrich). The developed blots were photographed using a digital camera, and the $M_{r}$ and density of each specific band were assessed using SigmaGel ${ }^{\mathrm{TM}}$ software (Jandel Corp., San Rafael, CA, USA).

Assay for the detection of immunopurified native PKC $\zeta$-specific activity. A fluorometric PKC activity assay kit, the Omnia ${ }^{\mathrm{TM}}$ Ser/Thr Recombinant Kit 8 (Life Technologies Italia), which included the Omnia ${ }^{\mathrm{TM}} \mathrm{S} / \mathrm{T}$-peptide-8 as a PKC $\zeta$-specific substrate, was used. To measure the specific activity $(\mu \mathrm{g} /$ protein) of the $\mathrm{PKC} \zeta$ isoforms immunoprecipitated from the NMs, the assay mixture was set up as according to the manufacturer's instructions. No co-factor was added to the immunocomplex-bearing beads, as the detection of PKC $\zeta$ basal activity does not need $\mathrm{Ca}^{2+}$, PS or DAG. Each sample was incubated in the presence or absence of a myristoylated PKC $\zeta$ pseudosubstrate inhibitor (Myr-SIYRRGARRWRKL-OH, $100 \mu \mathrm{M}$; Sigma-Aldrich) to confirm the specificity of PKC $\zeta$ activity. The amounts of phosphorylated S/T-peptide- 8 were determined by measuring fluorescence $\left(\lambda_{\mathrm{ex}} 360 \mathrm{~nm} ; \lambda_{\mathrm{em}}\right.$ $485 \mathrm{~nm}$ ) according to the manufacturer's instructions. The results were expressed in arbitrary units calculated for each sample as $\Delta \mathrm{F} \mu \mathrm{g}^{-1}$ immunoprecipitated protein.

Assay for the detection of caspase-3 activity. The specific activity of caspase-3 was measured using its specific 7-amido-4-methylcoumarin (AMC)-conjugated substrate, Acetyl-Asp-Met-Gln-Asp-AMC (Ac-DMQD-AMC; $50 \mu \mathrm{M}$; Bachem, Weil am Rhein, Germany) according to the procedure described in our previous study (20). The results were expressed in arbitrary units.

Isolation of p-caspase-3. Phosphoproteins were isolated using PhosphoCruz-Agarose $^{\mathrm{TM}}$ (Santa Cruz Biotechnology, Inc.) according to the manufacturer's instructions. Briefly, $300 \mu \mathrm{g} \mathrm{NM}$ proteins were diluted up to $1.0 \mathrm{ml}$ with $50 \mathrm{mM} \mathrm{MES,} 1.0 \mathrm{M} \mathrm{NaCl}$, $0.25 \%$ CHAPS pH 6.6 (binding/washing buffer), and reacted with PhosphoCruz-Agarose for $90 \mathrm{~min}$ at $4^{\circ} \mathrm{C}$ under swelling. Following 3 washes with binding/washing buffer, the phosphoproteins were eluted from PhosphoCruz-Agarose in $100 \mathrm{mM}$ ammonium bicarbonate, $0.25 \%$ CHAPS pH 9.0 (elution buffer) and assessed by western blot analysis using anti-caspase-3 antibody (clone 4-1-18; MAB4703; Merck Millipore, Milan, Italy).

Isolation of cytoplasms and nuclei for cell-free reconstituted $\mathrm{N}$-C constructs. We followed our previously described procedure (20). Untreated C4-I cells or C4-I cells treated with VP-16 for $24 \mathrm{~h}$ were harvested by scraping them into cold $\left(4^{\circ} \mathrm{C}\right) \mathrm{PBS}$. The cells were then washed twice by centrifugation/resuspen- 
sion cycles in cold PBS, and incubated on ice for $10 \mathrm{~min}$ at a density of $1.0 \times 10^{7}$ cells $/ \mathrm{ml}$ in lysis buffer $[150 \mathrm{mM} \mathrm{NaCl}$, $1.0 \mathrm{mM} \mathrm{KH} \mathrm{PO}_{4}, 5.0 \mathrm{mM} \mathrm{MgCl}, 1.0 \mathrm{mM}$ EGTA, $1.0 \mathrm{mM}$ dithiothreitol, $20 \mu \mathrm{M}$ sodium orthovanadate, $5.0 \mathrm{mM}$ sodium fluoride complete-EDTA-free protease inhibitor mixture (Roche Diagnostics GmbH, Milan, Italy), 5.0 mM HEPES (pH 7.4), $10 \%$ glycerol and $0.3 \%$ Triton X-100]. The lysates were then centrifuged $\left(2,000 \mathrm{x}\right.$ g for $10 \mathrm{~min}$ at $\left.4^{\circ} \mathrm{C}\right)$, and their supernatants were the cytoplasmic extracts $(C)$ from either untreated $(0 \mathrm{~h})$ cells or cells treated with VP-16 for $24 \mathrm{~h}$. Intact nuclei $(N)$ were isolated only from the untreated cells, washed twice by centrifugation/resuspension in lysis buffer without Triton X-100, and suspended at a final density of $1.0-2.0 \times 10^{7}$ nuclei $/ \mathrm{ml}$. Both types of cytoplasmic pools (4 volumes) were then incubated at $30^{\circ} \mathrm{C}$ for 30 min with $N$ isolated from untreated cells (1 volume), thus forming the reconstituted constructs (N-Cs). Of these, we experimentally used 4 types i.e., types $(a)$ and $(b)$, untreated $\mathrm{N}-\mathrm{Cs}$ minus/plus (respectively) a specific inhibitor of PKC $\zeta$ activity $(60 \mu \mathrm{M})$; and types $(c)$ and $(d), \mathrm{VP}-16$-treated $C$ 's plus untreated $N$ minus/plus (respectively) a specific inhibitor of PKC $\zeta$ activity $(60 \mu \mathrm{M})$ (Fig. 4A). p-Caspase-3 was assessed in the NM-immunoprecipitated phosphoprotein fraction (using PhosphoCruz-Agarose; Santa Cruz Biotechnology, Inc.) through western blot analysis with anti-caspase-3 antibody.

Suppression of Bcllo expression using small interfering RNA (siRNA). Chemically synthetic siRNA specifically suppressing Bcl10 protein synthesis was purchased from Qiagen (Milan, Italy). The sequences of this siRNA-Bcllo were as follows: sense, 5'-GAA UCU AUU CGG CGA GAAA-3', and antisense, 5'-UUU CUC GCC GAA UAG AUUC-3'. The cells were plated in 6-well plates at a density of $45 \times 10^{3}$ cells/well, transfected with siRNA-Bcl10 $(8.0 \mathrm{nM})$ using HiPerFect reagent in siRNA buffer as the vehicle (HPF; Qiagen), and cultured for $24 \mathrm{~h}$ according to the manufacturer's instructions. Subsequently, a second dose of siRNA-Bcl10 (8.0 nM) in HPF was administered simultaneously with VP-16 $(2.0 \mu \mathrm{g} / \mathrm{ml})$ at the experimental $0 \mathrm{~h}$ of the study and the cells were sampled $24 \mathrm{~h}$ later. Relevant transfection controls were as follows: i) cells were transfected with an Alexa Fluor 488-labeled scrambled siRNA sequence (Qiagen) and ii) cells were treated only with HPF. The entry of the transfection complexes into the C4-I cells was confirmed through observation under a fluorescence microscope (BX60 ${ }^{\mathrm{TM}}$; Olympus Italia, Segrate, Milan, Italy) of the cells that had been transfected with an Alexa Fluor 488-labeled scrambled siRNA sequence (data not shown). The effectiveness of silencing Bcl10 expression was determined by western blot analysis of the NMs and TCLs with an anti-Bcl10 monoclonal antibody (Santa Cruz Biotechnology, Inc.).

Bcl10-suppressing lentiviral iRNA (iBcl10) transactivation of C4-I cells. We used the human immunodeficiency virus type 1-derived lentiviral vector to generate a constitutively active pLKO.1-puro/Bcl10 vector which would then be used for the specific depletion of Bcl10. The most effective Bcl10-suppressing lentiviral constructs had target sequences that differed from those of the siRNA-Bcl10 (see above), that is: GTT GAA TCT ATT CGG CGA GAA or GAA GTG AAG AAG GAC GCC TTA. The recombinant lentivirus was produced by transducing HEK293FT cells using a ViraPower Lentiviral Expression system (Life Technologies Italia). Briefly, pLKO.1-puro/Bcl10 (3.0 $\mu \mathrm{g})$ was co-transduced in subconfluent HEK293FT cultures with the ViraPower Packaging Mix using Lipofectamine 2000. Lentiviruses were harvested $48 \mathrm{~h}$ later, filtered through a Millex-HV $0.45 \mu \mathrm{m}$ and stored at $-80^{\circ} \mathrm{C}$, according to the manufacturer's instructions. For RNA interference experiments, the viral stocks were added to the C4-I cells $\left(0.8 \times 10^{6}\right)$ supplemented with $4.0 \mu \mathrm{g} / \mathrm{ml}$ polybrene (Santa Cruz Biotechnology, Inc.). Infected cells were selected by incubation with $5.0 \mu \mathrm{g} / \mathrm{ml}$ puromycin (Sigma-Aldrich) for 4 days. A lentiviral non-target vector ( $n t)$ containing a short hairpin that does not recognize any human or mouse gene (MISSION pLKO.1-puro; Sigma-Aldrich) was used in parallel as a negative control in all the transduction experiments. The effectiveness of silencing Bcl10 expression was determined by western blot analysis of the TCLs and/or NMs with an anti-Bcl10 monoclonal antibody (Santa Cruz Biotechnology, Inc.).

Statistical analysis. One-way analysis of variance (ANOVA) with the post hoc Holm-Sidak test (both pair-wise multiple comparison procedures) were applied to the data, and a value of $\mathrm{P}<0.05$ was considered to indicate a statistically significant difference using the Sigmastat 3.5 ${ }^{\mathrm{TM}}$ software package (Systat Software Inc., Chicago, IL, USA).

\section{Results}

Apoptotic effects of VP-16 on C4-I cells. These effects have been previously detailed (20). For the present aims, we need only mention that the numbers of substrate-adherent viable cells (i.e., those with a typically patterned AO-stained DNA; those stained with EB were excluded) in the untreated cultures trebled between the experimental $0 \mathrm{~h}$ (i.e., $24 \mathrm{~h}$ after plating in F-175 flasks and the addition of fresh medium at $24 \mathrm{~h}$ ) and $72 \mathrm{~h}$. C4-I cell proliferation was inhibited immediately after the addition of etoposide (VP-16; $2.0 \mu \mathrm{g} / \mathrm{ml})$ and $24 \mathrm{~h}$ later the viable cell numbers began to decline $(72 \mathrm{~h},-61 \%$ vs. $0 \mathrm{~h} ; \mathrm{P}<0.01)$.

$P K C \zeta \bullet B c l 10 \bullet P D K 1$ complexes increase at NMs of apoptotic C4-I cells. PKC $\zeta$ activation requires the phosphorylation of $\mathrm{Thr}^{410}$ within its T-loop (which is effected by an upstream kinase, PDK1) (37). We first confirmed by western blot analysis the previous identification through PMF of PDK1 as an NM protein which co-immunoprecipitates with PKC $\zeta$ (20) (Fig. 1A). Furthermore, we found that following treatment with VP-16, the levels of PDK1 at the NMs increased significantly [ $24 \mathrm{~h}, 2.2$-fold; $48 \mathrm{~h}, 2.5$-fold vs. $0 \mathrm{~h}$; $\mathrm{P}<0.02$ in both instances vs. the $0 \mathrm{~h}$ (control) values] (Fig. 1A). Moreover, to determine the possible involvement of PDK1 in the functioning of the PKC $\zeta \bullet B c 110$ complexes, we used immunoprecipitation to examine whether PDK1 co-immunoprecipitates with Bcl10 and PKC $\zeta$ from the NMs of C4-I cells. We found that PKC $\zeta$ was associated with increasing levels of PDK1 $(24 \mathrm{~h}$, 3.0-fold; 48 h, 3.3-fold vs. 0 h; $\mathrm{P}<0.02$ in both instances vs. $0 \mathrm{~h}$ values) (Fig. 1B). Reverse co-immunoprecipitation assays performed using an anti-PDK1 ab confirmed PDK1's soaring association with $\mathrm{PKC} \zeta$ (data not shown). We also observed that at the NMs of VP-16-treated cells, Bcl10 co-immmuno- 


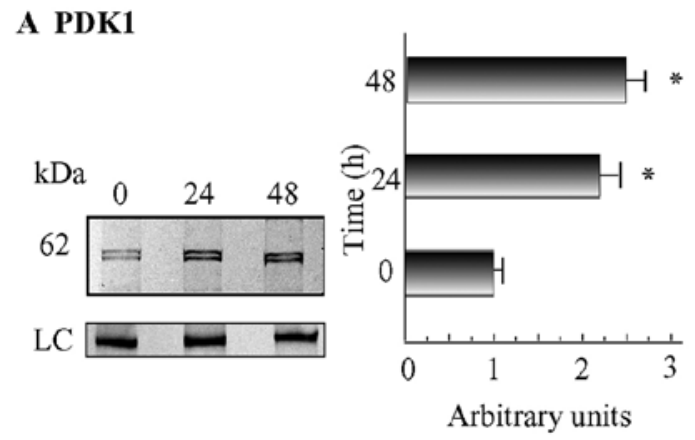

C IP Bcl10 anti-PDK1 ab

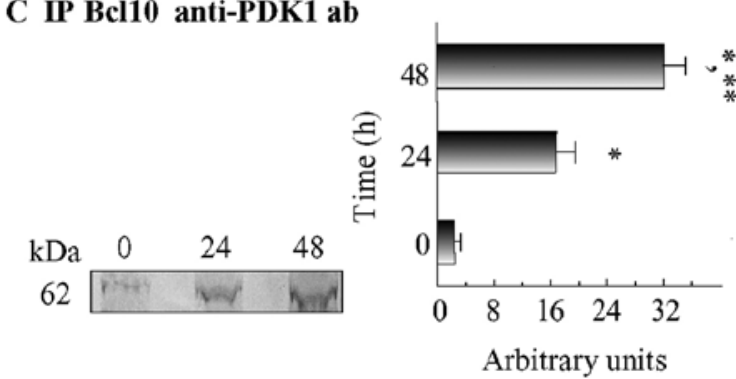

B IP PKC $\zeta$ anti-PDK1 ab

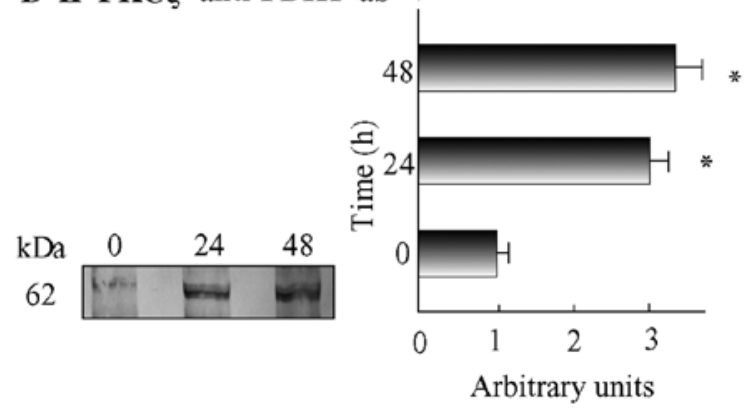

D IPPDK1 anti-Bcl10 ab

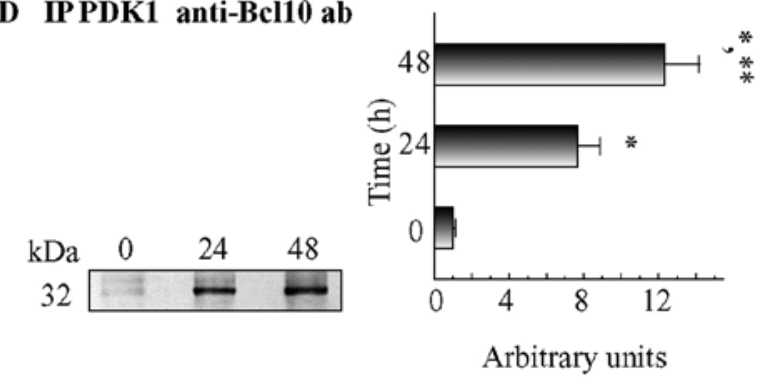

Figure 1. Time course of VP-16-elicited 3-phosphoinositide-dependent protein kinase-1 (PDK1) loading increase onto nuclear membranes (NMs) and PDK1 interactions there with B-cell lymphoma 10 (Bcl10) and protein kinase (PK)C $\zeta$ in wild-type (wt) C4-I cells. (A) With time, increasing amounts of PDK1 translocated onto the NMs of VP-16 $(2.0 \mu \mathrm{g} / \mathrm{ml})$-treated C4-I cells as compared with untreated ( 0 h) C4-I cells. (B) PDK1 co-immunoprecipitated with PKC $\zeta$ holoprotein from NMs of VP-16-treated C4-I cells in amounts that increased significantly with time. (C) Time-related, inglarge increases in PDK1 co-immunoprecipitating with Bcl10 from NMs of VP-16-treated C4-I cells as compared with untreated (0 h) C4-I cells. (D) Reverse co-immunoprecipitation confirmed time-related surges in the amounts of Bcl10 co-immunoprecipitating with PDK1 at NMs from VP-16-treated C4-I cells as compared with untreated (0 h) C4-I cells. Immunoprecipitation assays (B-D) were carried out as detailed in the Materials and methods. Representative blots are shown (A-D). Densitometric data (the means \pm SEM) pertaining to each specific protein band from the experimental group were normalized by taking 1.0 as the corresponding $0 \mathrm{~h}$ value and expressed in arbitrary units. ${ }^{*} \mathrm{P}<0.03$ vs. $0 \mathrm{~h}$ (controls), ${ }^{* * *} \mathrm{P}<0.03$ vs. $24 \mathrm{~h}$ values (C and D). LC, loading control (A); ab, antibody.

precipitated with increasing amounts of PDK1 (24 h, 17.5-fold and $48 \mathrm{~h}, 32$-fold vs. $0 \mathrm{~h} ; \mathrm{P}<0.001$ in both instances vs. the $0 \mathrm{~h}$ values) (Fig. 1C). Finally, at the NMs of the VP-16-treated cells, PDK1 was associated with increasing amounts of Bcl10 ( $24 \mathrm{~h}, 7.7$-fold and $48 \mathrm{~h}, 12.3$-fold vs. $0 \mathrm{~h}$; $\mathrm{P}<0.05$ in both instances vs. the $0 \mathrm{~h}$ values) (Fig. 1D). Taken together, these results indicate that $\mathrm{PKC} \zeta, \mathrm{Bcl} 10$ and $\mathrm{PDK} 1$ are joined together in heterotrimeric protein complexes that increasingly assemble over time at the NMs of apoptotic C4-I cells.

Bcllo knockdown prevents PDK1 from linking with/activating PKC $\zeta$ at NMs of apoptotic C4-I cells. The detected interaction of PDK1 with Bcl10 was particularly noteworthy, as we had previously reported that increasing amounts of assembled PKC $\zeta \cdot B c 110$ complexes accrued at the NMs of VP16-treated C4-I cells $(20,31)$. Therefore, in this study, we aimed to establish whether the specific knockdown of Bcl10 expression would hinder the assembly of PDK $1 \bullet P K C \xi$ complexes and, consequently, hinder the increase in $\mathrm{PKC} \zeta$ activity at the NMs of apoptotic C4-I cells. To this end, we used i) a specific siRNA targeting Bcl10 (siBcllo); and ii) a short hairpin Bcl10 mRNAsuppressing lentiviral vector $(\mathrm{iBcl} 10)$ targeting two nucleotide sequences differing from that aimed at by the siBcllo (see Materials and methods).

siBcl10. As shown in Fig. 2A, similar levels of Bcl10 protein were found in the blots of the TCLs of the untreated or VP-16-treated C4-I cells. A double administration (at -24 and $0 \mathrm{~h}$ ) of siBcl10 (8.0 $\mathrm{nM})$ dissolved in HPF suppressed, by $24 \mathrm{~h}, 78.0-80.3 \%$ of the Bcl10 protein level in the TCLs from both the untreated and VP-16-exposed C4-I cells. Notably, siRNA-mediated Bcl10 suppression brought about three interrelated effects at the NMs of the C4-I cells treated with VP-16 for $24 \mathrm{~h}:$ i) it prevented the increase in the assembly $(0 \mathrm{~h})$ of PKC $\zeta \cdot P D K 1$ complexes, thereby suppressing the 3 -fold increase otherwise elicited by VP-16 in the Bcl10-expressing cells (Fig. 2B); ii) it reduced below basal levels the PDK1-effected phosphorylation at $\mathrm{Thr}^{410}$ which activated the PKC $\zeta$ holoprotein, thereby obliterating the increase in $\mathrm{Thr}^{410}$ phosphorylation occurring in VP-16-treated Bcl10-expressing cells (Fig. 2C); and iii) it completely blocked the surge, over basal levels, of PKC $\zeta$ activity observed in VP-16-exposed Bcl10-expressing cells (Fig. 2D). Remarkably, these 3 effects were specific to the siRNA-mediated suppression of Bcl10, since treatment with a scrambled siRNA neither modified basal PKC $\zeta$ activity nor hindered its VP-16-elicited increase (Fig. 2D).

$i B c l 10$. We also explored the role(s) of Bcl10 in the association of PKC $\zeta$ with PDK1 using a Bcl10-suppressing lentiviral vector (iBcllO) and, as control, a non-target vector (inv). In keeping with previous our findings (20), Bcl10 levels remained steady in the TCL samples from the inv-transduced cells, whereas in the TCL samples from iBcl10-transduced cells, which were not treated with VP-16, these levels decreased by $\sim 82 \%(\mathrm{P}<0.001)$ after 72 and $96 \mathrm{~h}$ of puromycin selection (Fig. 3A). 


\section{A siRNA-Bc110}
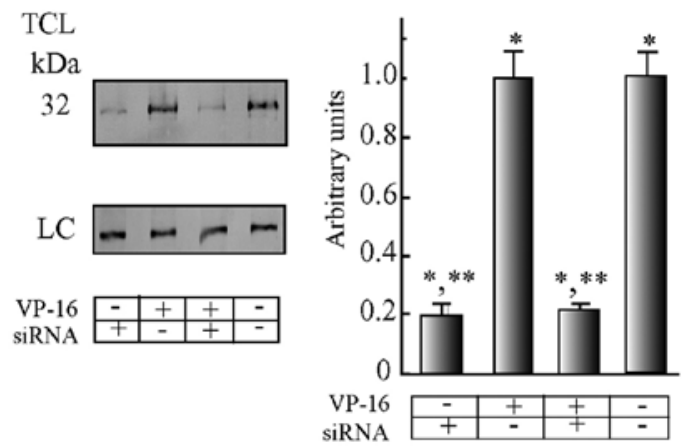

$\mathrm{C}\left(\mathrm{p}-\mathrm{Thr}^{410}\right)$ PKC $\zeta$ holoprotein

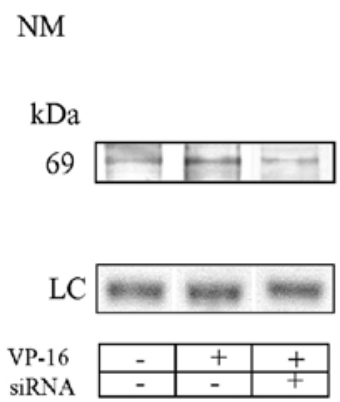

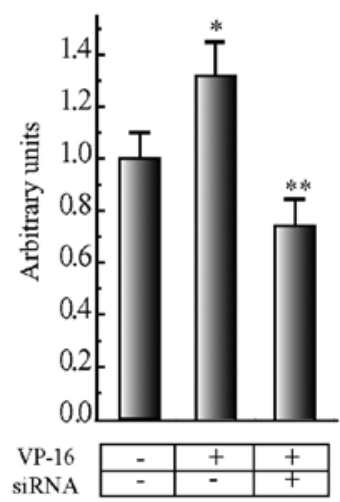

B IPPKC $\zeta$ anti-PDK1 ab

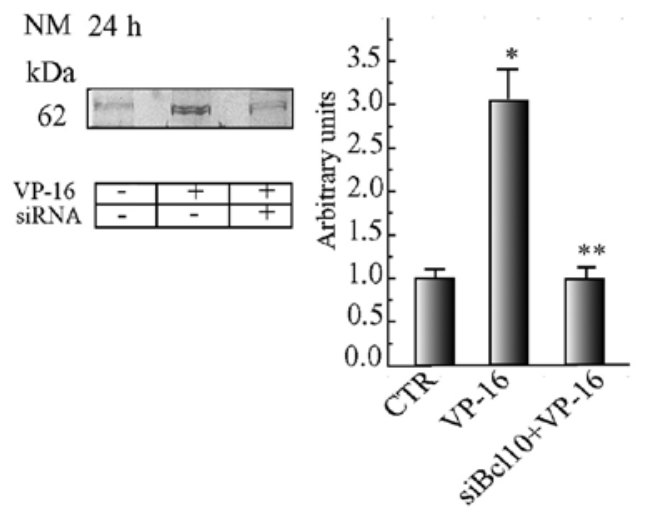

D IP PKC $\zeta$ activity

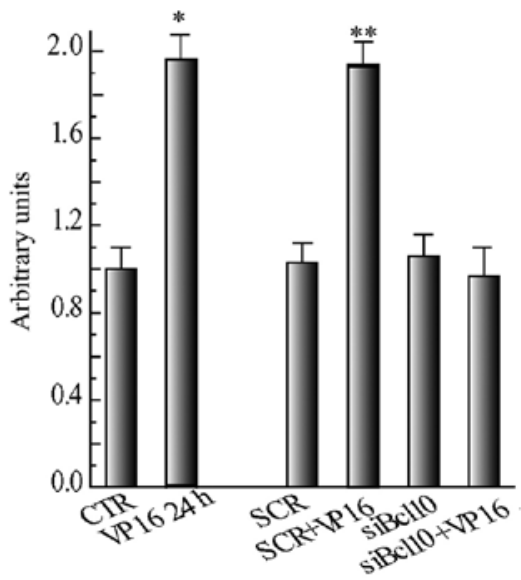

Figure 2. Suppression of B-cell lymphoma 10 (Bc110) expression by siRNA prevents 3-phosphoinositide-dependent protein kinase-1 (PDK1) from increasingly associating with protein kinase (PK)C $\zeta$ at the NE (nuclear envelope), thereby hindering the local surges in $\mathrm{PKC} \zeta$ phosphorylation and activity that would otherwise occur in VP-16-treated C4-I cells. (A) The amount of Bcl10 was similar in total cell lysates (TCLs) from both untreated and VP-16 (2.0 $\mu \mathrm{g} / \mathrm{ml})$-treated C4-I cells, but in both cases they were reduced substantially and by similar degrees following a double exposure (at -24 and 0 h) to a specific siRNA that mediated Bcl10 suppression (siBcl10; $8.0 \mathrm{nM}$ ) dissolved in HiPerFect reagent (HPF), as detailed in the Materials and methods. TCLs from harvested cells were immunoblotted with an anti-Bcl10 monoclonal antibody. (B) Bcl10 suppression by means of a specific siRNA (siBcl10) prevented PDK1 from increasing its levels of association with PKC $\zeta$ at the nuclear membrane (NM) fractions of cells treated with VP-16 for 24 h over the basal levels of untreated control (CTR) cells. PKC $\zeta$ was immunoprecipitated from equal aliquots of the NM fractions, and the immunoprecipitation samples were blotted and treated with an anti-PKD1 antibody. (C) Suppression of Bcl10 by siRNA also decreased to below starting $(0 \mathrm{~h})$ levels the phosphorylation at $\mathrm{Thr}^{410}$ of PKC $\zeta$ holoproteins, caused by PDK1, as revealed by a specific phosphorylated antibody (which, however, did not bind $\mathrm{p}-\mathrm{Thr}^{410}-\mathrm{PKC} \zeta$ catalytic fragments). Conversely, by $24 \mathrm{~h} \mathrm{p}-\mathrm{Thr}{ }^{40}-\mathrm{PKC} \zeta$ holoprotein was beginning to surge in C4-I cells treated with VP-16 alone. Cells were processed as in (B). (D) Suppression of Bcl10 by siRNA prevented the increase in NM-linked PKC $\zeta$ native-specific activity from happening by $24 \mathrm{~h}$ of VP-16 exposure (siBcllo + VP-16). By contrast, PKC $\zeta$ native-specific activity increased at the NMs of C4-I cells treated with VP-16 alone (VP-16 24 h). A scrambled (SCR) siRNA did not change the basal (0 h) levels of PKC $\zeta$-specific native activity assayed at the NM fractions of C4-I cells and did not hinder its increase $24 \mathrm{~h}$ after the addition of VP-16 (SCR + VP-16 24 h). CTR, untreated cells; siBcl10, $\mathrm{Bcl10}$-siRNA. Fluorometric assays of $\mathrm{PKC} \zeta$ activity were carried out as detailed in Materials and methods. Results are expressed in arbitrary units as $\Delta \mathrm{F} \mu \mathrm{g} / \mathrm{NM}$ protein. Representative western blots are shown on the left panels in (A-C). The corresponding densitometric data of the specific protein bands were normalized, taking as 1.0 the value of Bcl10 (A) or PDK1 (B) or p-Thr ${ }^{410}-\mathrm{PKC} \zeta$ holoprotein $(\mathrm{C})$ of the untreated $(0 \mathrm{~h})$ control specimens, and expressed in arbitrary units These data are presented as the means $\pm \mathrm{SE}$ ( $\mathrm{n}=4$ in all instances). (A-D) ${ }^{*} \mathrm{P}<0.02$ (at least) compared with untreated $(0 \mathrm{~h})$ cell values $(\mathrm{CTR}),{ }^{* * *} \mathrm{P}<0.05$ (at least) compared with values of cells treated with VP-16 alone. LC, loading control; ab, antibody.

At the NM, samples from iBcl10-transduced cells, not treated with VP-16 (puromycin selection $48 \mathrm{~h}=$ experimental $0 \mathrm{~h}$ time point), the levels of Bcl10 protein plummeted to $12.5 \%$ of those detected at NMs isolated from inv-transduced cells (Fig. 3B). However, a significant loading (10.5-fold vs. 0 h; $\mathrm{P}<0.001)$ of Bcl10 onto NMs took place $48 \mathrm{~h}$ after the addition of VP-16 to the inv-transduced cells (Fig. 3B). Conversely, Bcl10 translocation increased 13.5-fold at the NMs isolated from $i B c l 10$-transfected cells by $24 \mathrm{~h}$ vs. the corresponding $0 \mathrm{~h}$ controls, but changed little between 24 and $48 \mathrm{~h}$, and reached maximum levels that were only $\sim 20 \%$ of those found at the NMs of VP-16-treated inv-transduced cells at $48 \mathrm{~h}$ (Fig. 3B).
Hence, the suppression of Bcl10 significantly reduced Bcl10 translocation onto the NE.

The basal $(0 \mathrm{~h})$ levels of PDK1 co-immunoprecipitating with PKC $\zeta$ were similar at the NMs isolated from VP-16-untreated inv-transduced C4-I cells, or iBcllo-transfected C4-I cells or wt C4-I cells (Fig. 3C and cf. 1B). However, at the NMs isolated from VP-16-treated (24 and $48 \mathrm{~h}$ ) iBcllotransfected cells, the levels of PDK1-linked PKC $\zeta$ were not altered vs. the $0 \mathrm{~h}$ levels, revealing that with respect to the starting levels, no increase in the association between PKC $\zeta$ and PDK1 had occurred; this observation was at sharp variance with the increases in PDK1-PKC $\zeta$ complexes that were 
A iBcl10

TCL

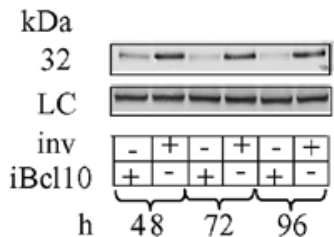

$=$ inv

$\square \mathrm{iBcl10}$

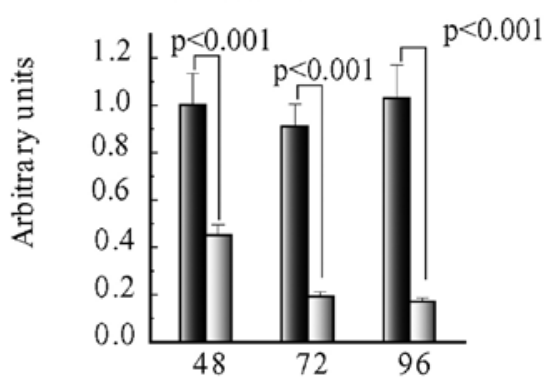

Time (h) Puromycin

\section{IP PKC $\zeta$ anti-PDK1 ab} $\mathrm{NM}$
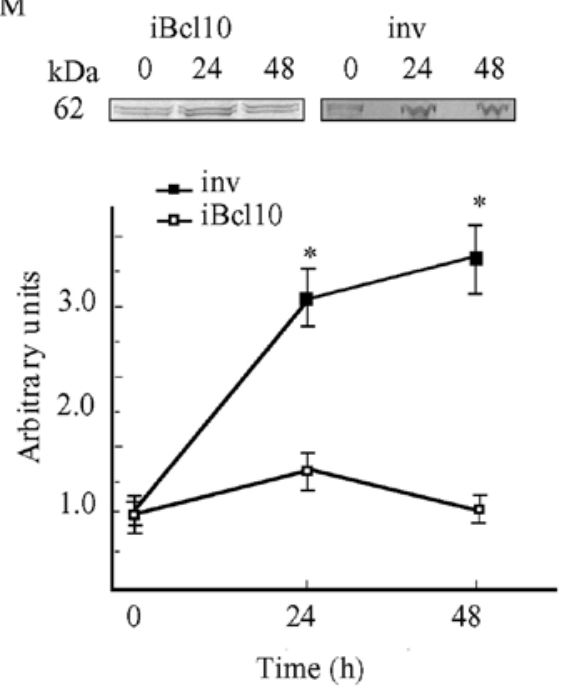

\section{B Bcl10 translocation}

NM
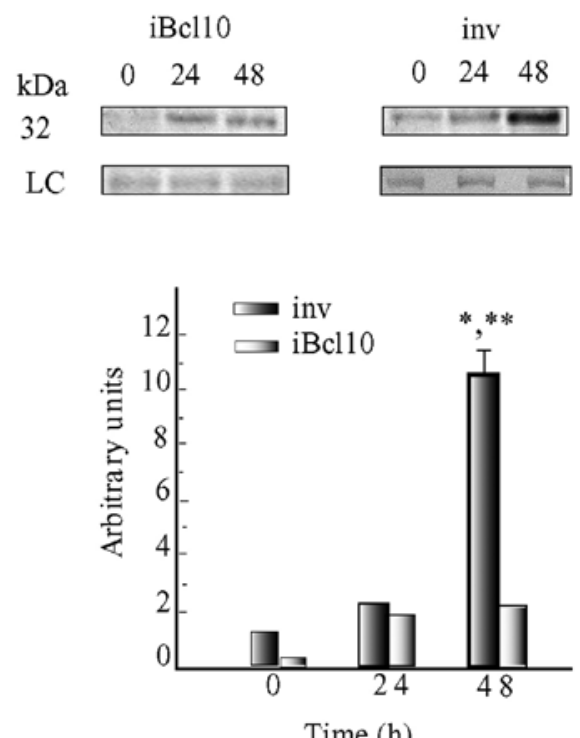

D IP PKC $\zeta$ activity

NM

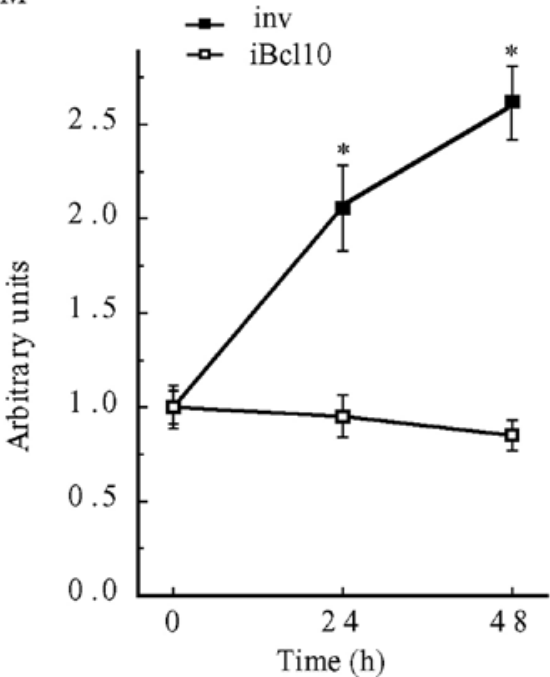

Figure 3. Effective lentiviral Bcl10 suppression inhibited B-cell lymphoma 10 (Bcl10) translocation onto nuclear membranes (NMs) and the assembly of 3-phosphoinositide-dependent protein kinase-1 (PDK1)-protein kinase (PK)C $\zeta$ complexes at NMs, thereby preventing the increase in PKC $\zeta$ activity at NMs isolated from VP-16-treated C4-I cells. (A) Bcl10 levels were effectively decreased in total cell lysates (TCLs) from iBcl10-transduced cells as compared to no target vector-infected (inv) cells. Equal amounts $(10 \mu \mathrm{g})$ of TCL proteins were immunoblotted and challenged with an anti-Bcl10 monoclonal antibody as detailed in Materials and methods. (B) Lentiviral Bcl10 suppression (iBcl10) markedly reduced Bcl10 loading onto NMs after 24 and 48 h of VP-16 treatment (corresponding to 72 and $96 \mathrm{~h}$ of puromycin selection) with respect to NMs from non-target vector transduced (inv) or wild-type (wt) cells (data not shown). (C) Lentiviral Bcl10 suppression (iBcl10) inhibited the co-immunoprecipitation of PDK1 with PKC $\zeta$ from NMs of VP-16-treated cells, which is at variance with what happened at NMs of inv-infected or wt cells (cf. Fig. 1B). PKC $\zeta$ was immunoprecipitated from equal protein aliquots of NMs; next the immunoprecipitation samples were blotted and challenged with an anti-PKD1 antibody as indicated in the Materials and methods. (D) Lentiviral suppression of Bcl10 (iBcl10) prevented the VP-16-elicited increase in PKC $\zeta$ native specific activity immunoprecipitated from NMs, which was at variance with what occurred in NMs from VP-16-treated inv or wt C4-I cells (data not shown). The experimental procedures were as described in (A). Representative blots are shown on the left panels in (A-C). The densitometric data (means $\pm \mathrm{SE}, \mathrm{n}=5$ ) pertaining to each specific protein band from each experimental group were normalized by taking as 1.0 the value of corresponding protein at $0 \mathrm{~h}$ and expressed in arbitrary units. PKC $\zeta$ native activity results (D) were similarly normalized. LC, loading control (A and B). Statistical analysis in B-D. ${ }^{*} \mathrm{P}<0.01$ vs. untreated $(0 \mathrm{~h})$ cell values, ${ }^{* *} \mathrm{P}<0.05$ vs. VP-16 alone-treated cells values. ab, antibody.

detected at the NMs from VP-16 treated inv-transduced and wt cells (Fig.x 3C and cf. 1B). Notably, immunoprecipitated PKC $\zeta$ native activity was not altered at the NMs from VP-16-treated $i B c l 10$-transfected cells, whereas it increased significantly at the NMs from VP-16-treated inv-transduced cells (Fig. 3D) and wt cells (data not shown).
PKC $\zeta$ promotes caspase-3 phosphorylation, enhancing its proteolytic activity at NMs of wt, but not siBcllo-transfected or iBcl10-transfected apoptotic C4-I cells. Caspase-3 has been previously identified as a protein that co-immunoprecipitates with the PKC $\bullet$ Bcl10 complexes at the NMs of VP-16-treated cells (20), and actively cleaves PKC $\zeta$. Thus, in this study, we 

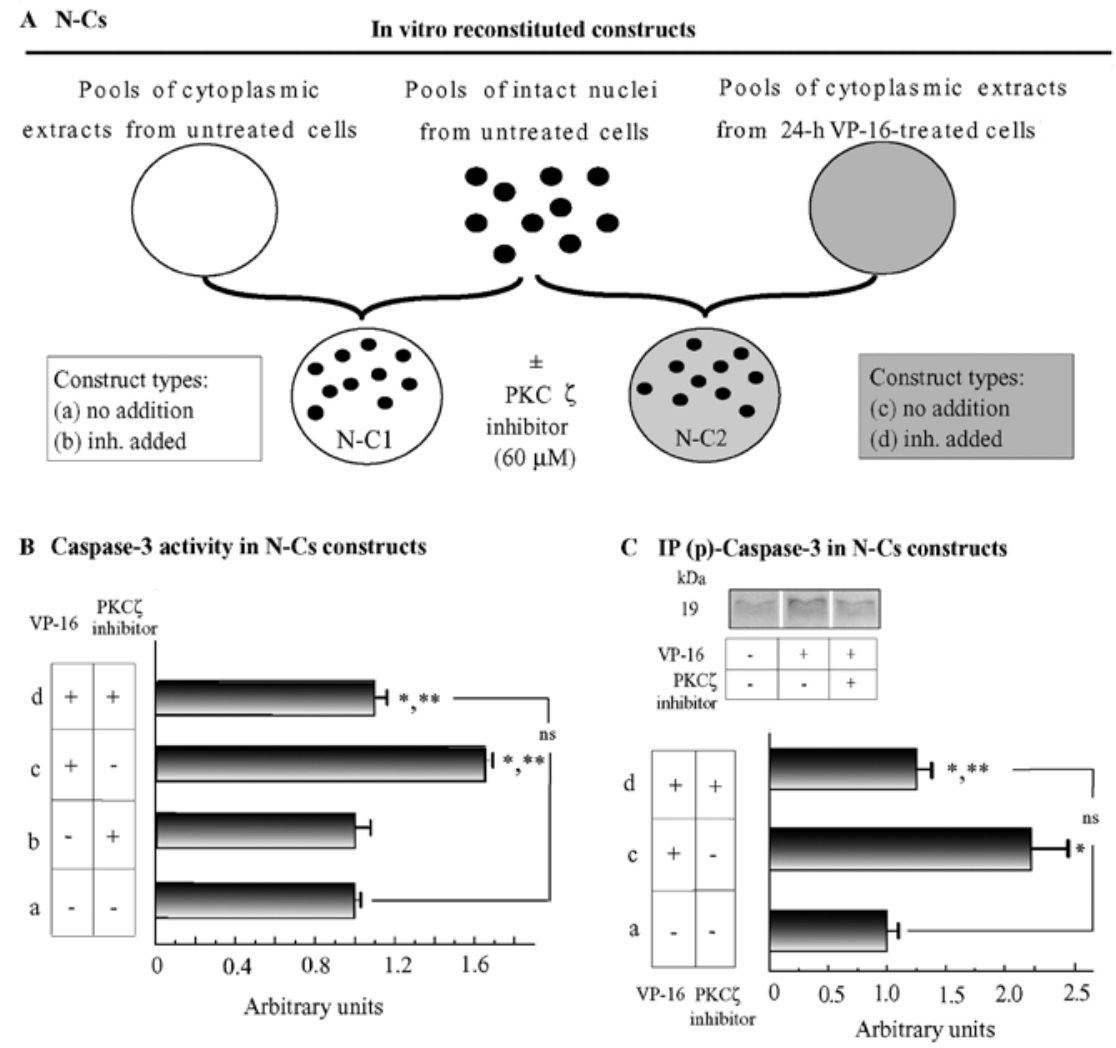

Figure 4. Protein kinase (PK)C $\zeta$ activity is required for the enhancement of caspase-3 activity at nuclear membranes (NMs) of apoptotic C4-I cells. (A) Schematic diagram of the 4 types $(a-d)$ of $\mathrm{N}$-Cs experimentally used in the present study; details are provided in the Materials and methods. (B) In type $(d) \mathrm{N}-\mathrm{Cs}$, the addition of a specific inhibitor of PKC $\zeta$ activity suppressed the VP-16-induced increase in NM-bound caspase-3 activity that occurred in the NM fractions of type (c) N-Cs. Details about the 4 types of $\mathrm{N}$-Cs used in the present experiments are shown in panel A. Data are presented as the means $\pm \mathrm{SE}(\mathrm{n}=4)$. ${ }^{*} \mathrm{P}<0.01($ at least) compared with type (a) values of $\mathrm{N}-\mathrm{Cs} .{ }^{* * *} \mathrm{P}<0.01$ (at least) compared with type $(b)$ values of $\mathrm{N}-\mathrm{Cs} .{ }^{* * *} \mathrm{P}<0.01$ (at least) compared with type $(c)$ values of $\mathrm{N}-\mathrm{Cs}$. (C) Levels of phosphorylated (p)-caspase-3 (p19 large sub-unit) increased markedly at NMs from type (c) N-Cs as compared with type (a) N-Cs. The suppression of PKC $\zeta$ activity by a specific inhibitor prevents the increase of p-caspase-3 at NMs from type $(d) \mathrm{N}$-Cs, as compared with type (c) N-Cs. Densitometric data corresponding to $\mathrm{p}$-caspase- 3 specific bands from $\mathrm{N}-\mathrm{C}$ experimental sets $(\mathrm{n}=4)$ are shown as the means $\pm \mathrm{SE}$ expressed as arbitrary units, and normalized taking as 1.0 the values at type $(a) \mathrm{N}$-Cs. ${ }^{*} \mathrm{P}<0.01$ (at least) compared with type $(a) \mathrm{N}$-Cs values. ${ }^{* *} \mathrm{P}<0.01$ (at least) compared with type $(c) \mathrm{N}-\mathrm{Cs}$ values.

aimed to define the interactions between caspase- 3 and the $\mathrm{PKC} \zeta \bullet \mathrm{Bcl} 10$ complex and determine whether PKC $\zeta$-specific activity has any influence on the association of caspase-3 with $\mathrm{PKC} \zeta \bullet \mathrm{Bcl} 10$ complexes. To address this issue, we used a PKC $\zeta$-specific pseudosubstrate inhibitor $(60 \mu \mathrm{M})$. This inhibitor curtailed $90 \%$ of $\mathrm{PKC} \zeta$ activity immunoprecipitated from the NMs of VP-16-treated C4-I cells, but at the same time was highly cytotoxic and caused massive cell death within $4 \mathrm{~h}$, which consequently obscured the results (data not shown). To overcome this hurdle, we generated 4 types of cell-free N-Cs, to which the PKC $\zeta$ pseudosubstrate inhibitor $(60 \mu \mathrm{M})$ was or was not added (Fig. 4A). The cell-free N-C constructs model consisted of intact nuclei from untreated $(0 \mathrm{~h})$ cells mixed with either cytoplasms from untreated $(0 \mathrm{~h})$ cells $(\mathrm{N}-\mathrm{Cl})$ or apoptotic cytoplasms from cells previously exposed to VP-16 for $24 \mathrm{~h}$ $(N-C 2)$. Note that the first $24 \mathrm{~h}$ are the time point when PKC $\zeta$ native-specific activity associated to Bcl10 doubled and showed a major increase in the VP-16-treated cells as compared to the control cells (see Fig. 3D). Both these constructs were incubated at $30^{\circ} \mathrm{C}$ for $30 \mathrm{~min}$ before their NMs were isolated. We found that adding the PKC $\zeta$ activity inhibitor wholly suppressed any increase in caspase-3 activity occurring at the NMs from $\mathrm{N}-\mathrm{C} 2$ constructs with respect to $\mathrm{N}-\mathrm{Cl}$ ones (Fig. 4B). Therefore, caspase- 3 recruitment and activation at the NE specifically required $\mathrm{PKC}-\zeta$ phosphorylating activity at the $\mathrm{NM}$ of apoptotic C4-I cells.

To validate this result, we investigated the phosphorylation levels of caspase-3 during VP16-induced apoptosis. We immunoprecipitated the phosphorylated proteins of the NMs isolated from $\mathrm{N}-\mathrm{C}$ constructs and then probed the immunoblots of the immunoprecipitated components with a specific anti-caspase-3 antibody. As shown in Fig. 4C, the levels of p-caspase-3 (p19 large sub-unit) increased markedly at the NMs of the VP16-treated C4-I cells, and this was prevented from occurring by the specific $\mathrm{PKC}-\zeta$ inhibitor.

Finally, we examined the effects of suppressing Bcl10 expression, using a specific siRNA or lentiviral vector on caspase- 3 activity. We found that $48 \mathrm{~h}$ after the addition of VP-16, caspase-3 activity co-immunoprecipitating with PKC $\zeta$ at the NMs of wt cells increased 5-fold $(\mathrm{P}<0.001)$ vs. the $0 \mathrm{~h}$ values (Fig. 5), thus reaching its maximum value and concurrently the amount of $\mathrm{PKC} \zeta$ catalytic fragments cleaved by caspase-3 progressively increased at the NMs topping by $48 \mathrm{~h}$ and $72 \mathrm{~h}$ of VP-16 treatment [for details see (19)]. By contrast, the suppression of Bcl10 by siBcllO or iBcllo prevented any increase in $\mathrm{PKC} \zeta$-associated caspase-3 activity from occurring in the apoptotic cells. These results indicated that $\mathrm{Bcl} 10$ nucleated complexes comprising PDK1, PKC $\zeta$ and caspase-3, 


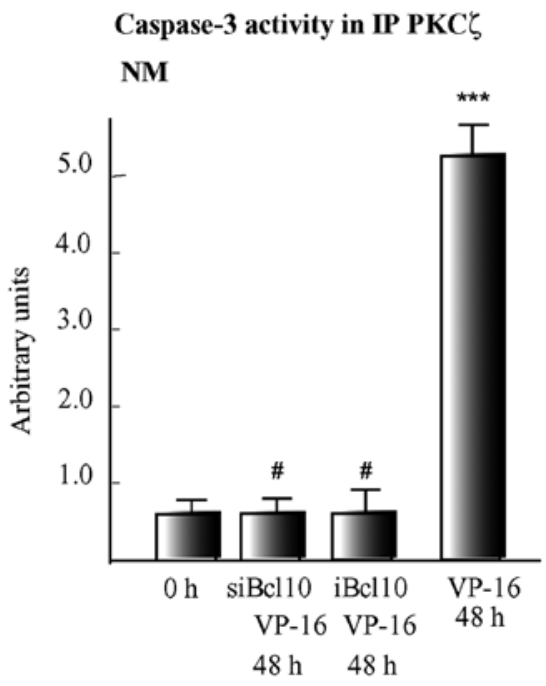

Figure 5. siRNA targeting B-cell lymphoma 10 (siBcllo) and lentiviral (iBcl10) suppression of Bcl10 prevented the increase in caspase-3 co-immunoprecipitated with protein kinase $(\mathrm{PK}) \mathrm{C} \zeta$ from the nuclear membranes $(\mathrm{NMs})$ of VP-16-treated C4I cells $(48 \mathrm{~h})$ as compared with untreated $(0 \mathrm{~h})$ cells. ${ }^{* * * *} \mathrm{P}<0.001$ vs. untreated $(0 \mathrm{~h})$ cells values or ${ }^{\#} \mathrm{VP}-16$-treated wild-type (wt) cell values.

which eventually led to the phosphorylation and enhancement of the activity of caspase-3, as previously shown (20), and in turn cleaved and inactivated the PKC $\zeta$ holoproteins.

Taken together, these results prove that, under VP-16 treatment, Bcl10 plays a crucial role at the NE by influencing the interaction between $\mathrm{PDK} 1$ and $\mathrm{PKC} \zeta$; this interaction allows PDK1 to phosphorylate at $\mathrm{Thr}^{410}$ and activate $\mathrm{PKC} \zeta$, and active PKC $\zeta$ to phosphorylate Bcl10. Next, phosphorylated Bcl10 causes a further interaction of PKC $\zeta$ with caspase-3 that enhances the proteolytic activity of the latter and effects the pro-apoptotic cleavage and inactivation of $\mathrm{PKC} \zeta$ (Fig. 5).

\section{Discussion}

PKC $\zeta$ is overexpressed in squamous HCCs, HeLa cells and C4-I cells $(20,38)$. In a previous study (20), we investigated the role(s) that PKC $\zeta$ plays at the NE of C4-I cells by analyzing, using proteomics analysis, the proteins with which $\mathrm{PKC} \zeta$ interacts. We found that 31 proteins and 33 proteins co-immunoprecipitated with $\mathrm{PKC} \zeta$ from the NMs, respectively, of proliferating (untreated) and VP-16-treated C4-I cells, respectively. Only 8 of these proteins, including the Bcl10 protein, were present in both types of NM samples. The identified $\mathrm{PKC}^{\xi}$-interacting NM proteins were assigned to 8 main functional groups, the relative percentage fractions of which differed in the NMs isolated from untreated vs. VP-16-treated cells. The protein groups related to transcription control, signal transduction and mitotic cell cycle regulation were prominent in the untreated NM samples, whereas in the VP-16-treated NM samples the protein group regulating programmed cell death was most prominent, followed by the signaling and transcription-regulating protein group. However, as previously noted, $71 \%$ of the signaling proteins, $86 \%$ of the apoptosis-regulating proteins, and $100 \%$ of the cell cycle- and transcription regulation-related and chaperone/adapter proteins were utterly dissimilar in the two situations considered (20).
Contentious opinions have been expressed in the past about the pro- or anti-apoptotic roles played by PKC $\zeta$ (39-41). Our results from proteomics analysis clearly demonstrated that PKC $\zeta$ changed nearly $86 \%$ of its interacting proteins at the NMs of C4-I cells. Therefore, we surmised that PKC $\zeta$ operates as a role-shifting kinase that interacts with and phosphorylates widely differing sets of NM proteins under conditions of growth or apoptosis (20).

In addition, in our previous study, we identified a hitherto unreported $\mathrm{PKC} \zeta \cdot \mathrm{Bcl} 10$ complex, the amount of which surged with time at the NMs of apoptotic C4-I cells (20). While selecting the $\mathrm{PKC} \zeta$-interacting NM proteins, we noted $\mathrm{Bcl10}$ since i) it co-immunoprecipitated with $\mathrm{PKC} \zeta$ from the NMs of both growing and apoptotic cells; and ii) in 2-DE gels of the VP-16-treated samples, we observed by $24 \mathrm{~h}$ a shift toward more acidic values of the pIs of both PKC $\zeta$ and $\mathrm{Bcl} 10$ vs. the $0 \mathrm{~h}$ values, which suggested that post-translational changes, e.g., phosphorylations, had occurred during this time lapse (20). We observed that $\mathrm{PKC} \zeta$ increasingly interacted with Bcl10 at the NMs of apoptotic C4-I cells and provided evidence that PKC $\zeta$ must be added to the group of the known Bcl10-phosphorylating kinases (20). Conversely, among the proteins interacting with $\mathrm{Bcl} 10 \bullet \mathrm{PKC} \zeta$ complexes at the same NMs we did not find any protein(s) already known to associate with Bcl10 or to partake with it in the CBM signalosomes (20). Bcl10 has been described as an apoptosis-regulating protein and tumor suppressor gene involved in NF- $\mathrm{B}$-mediated functions $(21,26,28,29,42,43)$. Hitherto, studies on Bcl10 have mostly been carried out on various types of lymphomas (44). In such tumors, Bcl10 is phosphorylated by several PKs, including $\mathrm{Ca}^{2+}$-calmodulin-dependent PKII, AKT1, p38-MAPK, IкB kinase and PKC $(21,30)$. Recently Kuo et al $(45)$ demonstrated that the suppression of Bcl10 by siRNA hindered the growth of 4 otherwise untreated HCC cell lines (i.e., C33A, CaSki, $\mathrm{HeLa}$ and $\mathrm{SiHa}$ ) through the $\mathrm{NF}-\kappa \mathrm{B}-$ dependent regulation of cyclin D1.

The results of our present study attest, to the best of our knowledge, for the first time that another PK, PDK1, associates with the $\mathrm{Bcl10} \bullet \mathrm{PKC} \zeta$ complexes, thus forming the $\mathrm{PDK} 1 \bullet \mathrm{Bc} 110 \bullet \mathrm{PKC} \zeta$ heterotrimer at the NMs of C4-I cells. Under basal (untreated) conditions, these heterotrimers are scanty at NMs. However, while undergoing VP-16-induced apoptosis, a massive increase of Bcl10, PDK1 and PKC $\zeta$ onto NMs and consequently an increasing assembly of the PDK1•Bcl10•PKC $\zeta$ complexes occur with time. In keeping with the well-established view that PDK1 phosphorylates at $\mathrm{Thr}^{410}$ and activates PKC $\zeta$ (37), we demonstrated in this study that this happens also in the PDK $1 \bullet \mathrm{Bcl} 10 \bullet \mathrm{PKC} \zeta$ complexes at the NMs of C4-I cells. However, we demonstrated in the present study that during VP-16-induced apoptosis, PDK1 interacts with $\mathrm{PKC} \zeta$ only when both proteins are complexed with Bcl10. The specific function of PDK1 has been shown to be regulated not only by its own phosphorylation, but also by protein-protein interactions and its subcellular localizations (33-35). We demonstrated in this study that the depletion of Bcl10 expression by either specific siRNA suppression or lentiviral transactivation wholly prevented the otherwise increasing interaction between PDK 1 and PKC $\zeta$ and, hence, the PKC $\zeta$-activating phosphorylation at $\mathrm{Thr}^{410}$ by PDK1. Therefore, according to our findings, during VP-16-induced apoptosis, 


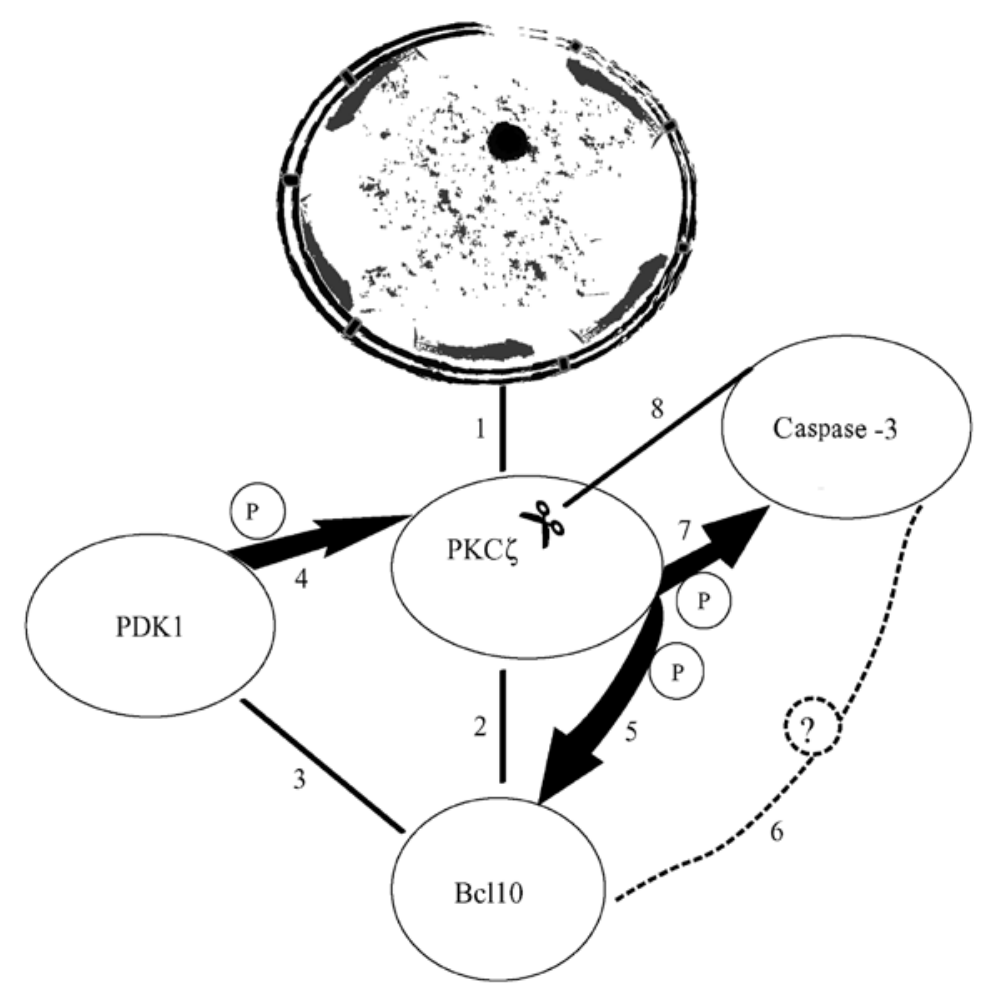

Figure 6. Depiction of the sequence of events leading to the assembly of a pro-apoptotic protein complex at the nuclear membranes (NMs) of C4-I cells following treatment with VP-16. (1) Initially, protein kinase (PK)C $\zeta$ increasingly connects with the nuclear envelope (NE). (2) B-cell lymphoma 10 (Bcl10) associates with NE-linked PKC . (3) Subsequently, 3-phosphoinositide-dependent protein kinase-1 (PDK1) associates with PKC $\bullet$ Bcl10, thus forming a heterotrimeric complex. (4) PDK1 then phosphorylates and activates PKC $\zeta$. (5) Activated phosphorylated (p)-PKC $\zeta$ in turn phosphorylates Bcl10. (6) p-Bcl10 is now capable of forming a new complex or enlarging the existing complex (as shown here), likely by incorporating a still unidentified member (dashed circle with question mark) that in turn binds to $19-\mathrm{kDa}$ caspase-3. (7) 19-kDa caspase-3 would then be phosphorylated by Bcl10-linked PKC $\zeta$, an event enhancing its proteolytic activity. (8) Finally, caspase-3 (whose activity is enhanced) cleaves the Bcl10-bound PKC $\zeta$ holoprotein. Reportedly, PKC $\zeta$ proteolysis causes a transient increase followed by a decrease in enzyme activity levels: this decrease in activity was observed between 48 and $72 \mathrm{~h}$ of VP-16 treatment in our model [Chiarini et al (19)] . An effective lentiviral or siRNA suppression of Bcl10 expression prevents the assembly of the multiprotein complex(es) and its consequences (cf. Figs. 2 and 3 ). Therefore, Bcl10 plays a pivotal role, mediating the unidirectional regulation of PKC $\zeta$ by PDK1 and the bidirectional pro-apoptotic interactions between $19 \mathrm{kDa}$ caspase- 3 and active PKC $\zeta$. For clarity, the size of the multiprotein complexes shown has been enlarged out of proportion with respect to the nucleus it binds.

Bcl10 acts as the essential pivot which nucleates the assembly of PDK1・Bcl10•PKC $\zeta$ complexes at NMs.

The influence of Bcl10 at the NMs of apoptotic C4-I cells is far reaching and is triggered by the phosphorylation of Bcl10 on PDK1-activated PKC $\zeta$ (20). Since the specific depletion of $P K C \zeta$ through lentiviral iRNA transactivation prevents the accumulation of Bcl10 at NMs in apoptotic C4-I cells, it seems likely that $\mathrm{PKC} \zeta$ first translocates to the NE; secondly, it enlists Bcl10 there; thirdly, it is phosphorylated and activated by Bcl10-recruited PDK1; and fourthly, it phosphorylates Bcl10 (20) (Fig. 6). p-Bcl10 then nucleates a second complex (or expands the first one) comprising PKC $\xi$ and active caspase-3. This is revealed by results gained by the specific lentiviral-transduced or siRNA-mediated depletion of Bcl10, demonstrating that under these conditions the progressive proteolytic cleavage and functional inactivation of PKC $\zeta$ by active caspase-3 no longer take place (20). Of note, Yan et al (28) reported that in 293T and MCF7 cells, Bcl10 interacts via a specific CARD with the upstream pro-caspase-9, thus mediating the autoproteolytic activation of the latter through oligomerization (another proapototic activity of Bcl10). Conversely, in the same cell types, the downstream effector caspase-3 failed to co-immunoprecipitate with Bcl10 (28). The authors pointed out that their evidence had intrinsic flaws since it was based upon ectopically overexpressed proteins, and that the operative mechanism(s) through which Bcl10 induced apoptosis remained unclear (28). In our previous study (20), the C4-I cells did not overexpress any protein, nor did we detect caspase-9 association with Bcl10. By contrast, we found that caspase- 3 co-immunoprecipitated with the PKC $\zeta$ complexes from the NMs of VP-16-treated cells. It is increasingly recognized that the activation of caspases is controlled by several mechanisms, including protein-protein interactions, post-translational modifications and phosphorylations by specific kinases $(46,47)$. Our findings indicate that caspase-3 co-immunoprecipitated with $\mathrm{PKC} \zeta$ complexes from the NMs of VP-16-treated cells. The association with PKC $\zeta$ suggests that caspase- 3 is one of the main substrates for Bcl10-bound PDK1-activated PKC $\zeta$ during apoptosis. We have not directly proved that caspase- 3 is a PKC $\zeta$ substrate in vitro, but by using cell-free in vitro reconstituted $\mathrm{N}-\mathrm{C}$ constructs we provide evidence that the enhancement of caspase- 3 activity requires functionally mature $\mathrm{PKC} \zeta$. The suppression of $\mathrm{PKC} \zeta$ activity by a specific inhibitor (highly cytotoxic to whole cells) prevented the increased phosphorylation of $19-\mathrm{kDa}$ caspase-3 and the enhancement of its activity in the N-C constructs. In this regard, Voss et al (48) demonstrated in human monocytes that PKCס, another PKC isoform, asso- 
ciated with caspase-3 and phosphorylated it in vitro, thereby enhancing caspase-3 activity. Moreover, in our model, when Bcl10 expression was suppressed, caspase-3 did not co-immunoprecipitate with the $\mathrm{Bcl} 10 \bullet \mathrm{PKC} \zeta$ complexes. Therefore, it seems feasible that $\mathrm{PKC} \zeta$-phosphorylated $\mathrm{Bcl10}$ either directly or through one or more yet to be identified go-between(s) links caspase-3 moieties to the phosphorylated Bcl10•PKC $\zeta$ complexes (Fig. 6). This would allow PKC $\zeta$ to phosphorylate and activate caspase-3, and in turn, activated caspase- 3 would cleave and inactivate PKC $\zeta$ (Fig. 6).

Hence, the assembled phosphorylated $\mathrm{Bcl10} \bullet \mathrm{PKC} \xi$ complexes associate with caspase-3, and thus it is clear that they play a pro-apoptotic role at the NMs of VP-16-treated C4-I cells. These results permit us to surmise that both $\mathrm{PKC} \zeta$ and $\mathrm{Bcl} 10$ are potential targets for novel approaches to HCC therapy.

\section{Acknowledgements}

This study was partly supported by the Italian Ministry of Education, University and Research (MIUR; FUR 2013/4). We are deeply grateful to Professor Nicole Murray and Professor Alan Fields (Mayo Clinic, Jacksonville, Florida, USA) for their useful comments on lentiviral transduction experiments and to Dr Maddalena Marconi for her skillful technical assistance.

\section{References}

1. Mukherjee S, Dey S, Bhattacharya RK and Roy M: Isothiocyanates sensitize the effect of chemotherapeutic drugs via modulation of protein kinase $\mathrm{C}$ and telomerase in cervical cancer cells. Mol Cell Biochem 330: 9-22, 2009.

2. Scarinci IC, Garcia FA, Kobetz E, Partridge EE, Brandt HM, Bell MC, Dignan M, Ma GX, Daye JL and Castle PE: Cervical cancer prevention: new tools and old barriers. Cancer 116: $2531-2542,2010$

3. Molano M, Van den Brule A, Plummer M, Weiderpass E, Posso H, Arslan A, Meijer CJ, Muñoz N and Franceschi S; HPV Study Group: Determinants of clearance of human papillomavirus infections in Colombian women with normal cytology: a population-based, 5-year follow-up study. Am J Epidemiol 158: 486-494, 2003

4. Perez-Plasencia C, Duenas-Gonzalez A and Alatorre-Tavera B: Second hit in cervical carcinogenesis process: involvement of wnt/beta catenin pathway. Int Arch Med 1: 10, 2008.

5. Kwasniewska A, Postawski K, Gozdzicka-Jozefiak A Kwasniewski W, Grywalska E, Zdunek M and Korobowicz E: Estrogen and progesterone receptor expression in HPV-positive and HPV-negative cervical carcinomas. Oncol Rep 26: 153-160, 2011.

6. Zhu X, Lv J, Yu L, Zhu X, Wu J, Zou S and Jiang S: Proteomic identification of differentially-expressed proteins in squamous cervical cancer. Gynecol Oncol 112: 248-256, 2009.

7. Higareda-Almaraz JC, Enríquez-Gasca MR,Hernández-OrtizM, Resendis-Antonio O and Encarnación-Guevara S: Proteomic patterns of cervical cancer cell lines, a network perspective. BMC Syst Biol 5: 96, 2011.

8. Carlson MW, Iyer VR and Marcotte EM: Quantitative gene expression assessment identifies appropriate cell line models for individual cervical cancer pathways. BMC Genomics 8: 117-129, 2007.

9. Dempsey EC, Newton AC, Mochly-Rosen D, Fields AP, Reyland ME, Insel PA and Messing RO: Protein kinase C isozymes and the regulation of diverse cell responses. Am J Physiol Lung Cell Mol Physiol 279: L429-L438, 2000.

10. Reyland ME: Protein kinase $\mathrm{C}$ isoforms: multi-functional regulators of cell life and death. Front Biosci (Landmark Ed) 14: 2386-2399, 2009.

11. Breitkreutz D, Braiman-Wiksman L, Daum N, Denning MF and Tennenbaum T: Protein kinase $C$ family: on the crossroads of cell signaling in skin and tumor epithelium. J Cancer Res Clin Oncol 133: 793-808, 2007.
12. Diaz-Meco MT, Dominguez I, Sanz L, Dent P, Lozano J, Municio MM, Berra E, Hay RT, Sturgill TW and Moscat J: zeta PKC induces phosphorylation and inactivation of I kappa B-alpha in vitro. EMBO J 13: 2842-2848, 1994.

13. Filomenko R, Poirson-Bichat F, Billerey C, Belon JP, Garrido C, Solary E and Bettaieb A: Atypical protein kinase $\mathrm{C}$ zeta as a target for chemosensitization of tumor cells. Cancer Res 62: 1815-1821, 2002.

14. Malhas AN and Vaux DJ: The nuclear envelope and its involvement in cellular stress responses. Biochem Soc Trans 39: 1795-1798, 2011.

15. Dal Pra I, Whitfield JF, Chiarini A and Armato U: Changes in nuclear protein kinase C-delta holoenzyme, its catalytic fragments, and its activity in polyomavirus-transformed pyF111 rat fibroblasts while proliferating and following exposure to apoptogenic topoisomerase-II inhibitors. Exp Cell Res 249: 147-160, 1999.

16. Chiarini A, Whitfield JF, Armato U and Dal Pra I: Protein kinase C-beta II Is an apoptotic lamin kinase in polyomavirus-transformed, etoposide-treated pyF111 rat fibroblasts. J Biol Chem 277: 18827-18839, 2002.

17. Chiarini A, Whitfield JF, Armato U and Dal Pra I: VP-16 (etoposide) and calphostin $\mathrm{C}$ trigger different nuclear but akin cytoplasmic patterns of changes in the distribution and activity of protein kinase C-betaI in polyomavirus-transformed pyF111 rat fibroblasts. Int J Mol Med 17: 111-120, 2006.

18. Chiarini A, Whitfield JF, Pacchiana R, Armato U and Dal Pra I: Photoexcited calphostin C selectively destroys nuclear lamin $\mathrm{B} 1$ in neoplastic human and rat cells - a novel mechanism of action of a photodynamic tumor therapy agent. Biochim Biophys Acta 1783: 1642-1653, 2008.

19. Watanabe Y, Hoshiai H, Nakanishi T, Kawamura N, Tanaka N, Isaka K, Kamiura S, Ohmichi M, Hatae M and Ochiai K: Evaluation of oral etoposide in combination with cisplatin for patients with recurrent cervical cancer: long-term follow-up results of a Japanese multicenter study. Anticancer Res 31: 3063-3067, 2011.

20. Chiarini A, Marconi M, Pacchiana R, Dal Prà I, Wu J and Armato U: Role-shifting PKC $\zeta$ fosters its own proapoptotic destruction by complexing with $\mathrm{Bcl} 10$ at the nuclear envelope of human cervical carcinoma cells: a proteomic and biochemical study. J Proteome Res 11: 3996-4012, 2012.

21. Willis TG, Jadayel DM, Du M-Q, Peng H, Perry AR, Abdul-Rauf M, Price H, Karran L, Majekodunmi O, Wlodarska I, et al: $\mathrm{Bcl10}$ is involved in $\mathrm{t}(1 ; 14)(\mathrm{p} 22 ; \mathrm{q} 32)$ of MALT B cell lymphoma and mutated in multiple tumor types. Cell 96: 35-45, 1999.

22. Chen M, Li LY and Qi Y-P: Bcl10 protein can act as a transcription activator in yeast. Mol Cell Biochem 246: 97-103, 2003.

23. Liu Y, Dong W, Chen L, Zhang P and Qi Y: Characterization of Bcl10 as a potential transcriptional activator that interacts with general transcription factor TFIIB. Biochem Biophys Res Commun 320: 1-6, 2004.

24. Thome M and Weil R: Post-translational modifications regulate distinct functions of CARMA1 and BCL10. Trends Immunol 28: 281-288, 2007.

25. Ruland J, Duncan GS, Elia A, del Barco Barrantes I, Nguyen L, Plyte S, Millar DG, Bouchard D, Wakeham A, Ohashi PS and Mak TW: Bcl10 is a positive regulator of antigen receptor-induced activation of NF-kappaB and neural tube closure. Cell 104: 33-42, 2001.

26. Zhang Q, Siebert R, Yan M, Hinzmann B, Cui X, Xue L, Rakestraw KM, Naeve CW, Beckmann G, Weisenburger DD, et al: Inactivating mutations and overexpression of BCL10, a caspase recruitment domain-containing gene, in MALT lymphoma with $\mathrm{t}(1 ; 14)(\mathrm{p} 22 ; \mathrm{q} 32)$. Nat Genet 22: 63-68, 1999.

27. Lambers AR, Gumbs C, Ali S, Marks JR, Iglehart JD, Berchuck A and Futreal PA: Bcl10 is not a target for frequent mutation in human carcinomas. Br J Cancer 80: 1575-1576, 1999.

28. Yan M, Lee J, Schilbach S, Goddard A and Dixit V: mE10, a novel caspase recruitment domain-containing proapoptotic molecule. J Biol Chem 274: 10287-10292, 1999.

29. Koseki T, Inohara N, Chen S, Carrio R, Merino J, Hottiger MO, Nabel GJ and Núñez G: CIPER, a novel NF kappaB-activating protein containing a caspase recruitment domain with homology to Herpesvirus-2 protein E10. J Biol Chem 274: 9955-9961, 1999.

30. Yui D, Yoneda T, Oono K, Katayama T, Imaizumi K and Tohyama M: Interchangeable binding of Bcl10 to TRAF2 and cIAPs regulates apoptosis signaling. Oncogene 20: 4317-4323, 2001. 
31. Pacchiana R, Abbate M, Armato U, Dal Prà I and Chiarini A: Combining immunofluorescence with in situ proximity ligation assay: a novel imaging approach to monitor protein-protein interactions in relation to subcellular localization. Histochem Cell Biol 142: 593-600, 2014.

32. Bayascas JR: Dissecting the role of the 3-phosphoinositide-dependent protein kinase-1 (PDK1) signalling pathways. Cell Cycle 7: 2978-2982, 2008.

33. Casamayor A, Morrice NA and Alessi DR: Phosphorylation of Ser-241 is essential for the activity of 3-phosphoinositide-dependent protein kinase-1: identification of five sites of phosphorylation in vivo. Biochem J 342: 287-292, 1999.

34. Kikani CK, Dong LQ and Liu F: 'New'-clear functions of PDK1: beyond a master kinase in the cytosol? J Cell Biochem 96 : $1157-1162,2005$

35. Sephton CF, Zhang D, Lehmann TM, Pennington PR, Scheid MP and Mousseau DD: The nuclear localization of 3'-phosphoinositide-dependent kinase-1 is dependent on its association with the protein tyrosine phosphatase SHP-1. Cell Signal 21: 1634-1644, 2009.

36. Lee KY, D'Acquisto F, Hayden MS, Shim JH and Ghosh S: PDK1 nucleates T cell receptor-induced signaling complex for NF-kappaB activation. Science 308: 114-118, 2005.

37. Hodgkinson CP and Sale GJ: Regulation of both PDK1 and the phosphorylation of PKC-zeta and -delta by a C-terminal PRK2 fragment. Biochemistry 41: 561-569, 2002.

38. Yu LR, Lv JQ, Jin LY, Ding SD, Ma XY, Wang JJ and Zhu XQ: Over-expression of protein kinase $\mathrm{C}$ isoforms $(\alpha, \delta, \theta$ and $\zeta)$ in squamous cervical cancer. Neoplasma 58: 491-498, 2011.

39. Hirai $T$ and Chida K: Protein kinase Czeta (PKCzeta): Activation mechanisms and cellular functions. J Biochem 133: 1-7, 2003.

40. Xin M, Gao F, May WS, Flagg T and Deng X: Protein kinase Czeta abrogates the proapoptotic function of Bax through phosphorylation. J Biol Chem 282: 21268-21277, 2007.
41. Nazarenko I, Jenny M, Keil J, Gieseler C, Weisshaupt K, Sehouli J, Legewie S, Herbst L, Weichert W, Darb-Esfahani S, et al: Atypical protein kinase $\mathrm{C}$ zeta exhibits a proapoptotic function in ovarian cancer. Mol Cancer Res 8: 919-934, 2010.

42. Yoneda T, Imaizumi K, Maeda M, Yui D, Manabe T, Katayama T, Sato N, Gomi F, Morihara T, Mori Y, et al: Regulatory mechanisms of TRAF2-mediated signal transduction by Bcl10, a MALT lymphoma-associated protein. J Biol Chem 275: 11114-11120, 2000.

43. Rosebeck S, Rehman AO, Lucas PC and McAllister-Lucas LM: From MALT lymphoma to the CBM signalosome: three decades of discovery. Cell Cycle 10: 2485-2496, 2011.

44. Yeh PY, Kuo S-H, Yeh K-H, Chuang SE, Hsu C-H, Chang WC, Lin H-I, Gao M and Cheng A-L: A pathway for tumor necrosis factor-alpha-induced Bcl10 nuclear translocation. Bcl10 is up-regulated by NF-kappaB and phosphorylated by Akt1 and then complexes with Bcl3 to enter the nucleus. J Biol Chem 281: $167-175,2006$.

45. Kuo SH, Chou CH, Cheng AL, Wang CW, Chen $\mathrm{YH}$ and Chen RJ: Expression of BCL10 in cervical cancer has a role in the regulation of cell growth through the activation of NF- $\kappa \mathrm{B}-$ dependent cyclin D1 signaling. Gynecol Oncol 126: 245-251, 2012.

46. Parrish AB, Freel CD and Kornbluth S: Cellular mechanisms controlling caspase activation and function. Cold Spring Harb Perspect Biol 5: a008672, 2013.

47. Kurokawa $\mathrm{M}$ and Kornbluth S: Caspases and kinases in a death grip. Cell 138: 838-854, 2009.

48. Voss OH, Kim S, Wewers MD and Doseff AI: Regulation of monocyte apoptosis by the protein kinase Cdelta-dependent phosphorylation of caspase-3. J Biol Chem 280: 17371-17379, 2005. 